SCIDic

\section{Evaluating The Incidence Of Distal Caries In Mandibular Second Molars Due To Mesioangularly Impacted Mandibular Third Molars}

Research Article

Sneha Krishnan, Senthilnathan Periasamy*, Murugaiyan Arun

Department of Oral and Maxillofacial Surgery, Saveetha Dental College, Saveetha Institute of Medical and Technical Sciences (SIMATS), Saveetha University, Chennai, India.

\title{
Abstract
}

To evaluate the incidence of caries on the distal aspect of mandibular second molars in patients referred for mesioangularly impacted mandibular third molar assessment. This retrospective study involved 167 patients out of which 98 were male and 69 were female who reported to the Oral Surgery Clinic at Department of Oral and Maxillofacial Surgery, Saveetha Dental College, Chennai. Clinical and radiographic data from 167 patients were ascertained over a ten month period from June 2019-March 2020. Parameters such as age, gender, presence of distal caries, side of lower jaw frequently affected, Pederson difficulty index, were evaluated and assessed by a single examiner and reviewed by two independent investigators.In this study, a total of 167 mesioangular mandibular third molars were included and assessed. The incidence of caries affecting the distal aspect of the second molar adjacent to mesioangularly impacted mandibular third molar was $35.33 \%$, with a significant predilection towards the left side of the lower jaw $(50.8 \%)$. The age frequently showing distal caries adjacent to mesioangularly impacted mandibular third molar was in the age group between $21-30$ years $(55.93 \%)$, with a significant female predilection $(35.33 \%)$.Within the limits of this study, there is a significant association between incidence of distal caries on mandibular second molar and adjacent mesioangularly impacted mandibular third molar, with a significant female predilection.

Keywords: Mesioangular; Distal Caries; Impaction; Third Molar; Second Molar; Orthopantomograms.

\section{Introduction}

Third molars generally erupt between the ages of 17 and 24 years however there is a wide variation in eruption times and some wisdom teeth may still emerge even beyond the fifth decade of life $[20,42]$. Wisdom teeth may erupt into the correct dental position and become functional or conversely, they may emerge in a non-functional or only partly functional positions that are termed impacted [41]. The reason for their extraction could be due to its impaction or its potential complications damaging the adjacent teeth or the involved tooth itself [14].

Impaction is defined as the failure of tooth eruption into a normal position caused by an obstacle in the eruption path, abnormal positioning of a tooth, lack of space, or other impediments [37]. Incidence of impacted third molars is more common in the mandible $(90 \%)$ than the maxilla [36]. Surgical removal of im- pacted molars is one of the most frequent operations in the field of oral and maxillofacial surgery [4]. Impacted third molars are known to be possible causes of pericoronitis [9], mandible angle fractures [13] cystic lesions, and caries of the mandibular second molars $[2,11,25]$. Thus, it may also cause detrimental effects on adjacent tooth as reported by Mc Grath et al (2003), ChaperroAvendano et al. (2005), [43]. Factors affecting prevalence can be the age group, timing of dental eruption, and radiographic criteria for dental development [5].

The prevalence of caries on the mandibular second molar due to presence of a third, partially erupted third molar, varies between $7 \%$ and $32 \%[6,8,22,29]$. Mesioangular wisdom teeth which are partially or fully erupted have been implicated in the development of caries in the distal aspect of the corresponding second molar [19, 22, 25]. Mesioangularly impacted mandibular third molars showed pathologic lesions most frequently [16].

\section{*Corresponding Author:}

Prof. Dr. Senthilnathan Periasamy MDS.

Department of Oral and Maxillofacial Surgery, Saveetha Dental College, Saveetha Institute of Medical and Technical Sciences (SIMATS), Saveetha University, Chennai, India. Tel: 9340040030

E-mail: senthilnathan@saveetha.com

Received: August 12, 2020

Accepted: August 29, 2020

Published: August 30, 2020

Citation: Sneha Krishnan, Senthilnathan Periasamy, Murugaiyan Arun. Evaluating The Incidence Of Distal Caries In Mandibular Second Molars Due To Mesioangularly Impacted Mandibular Third Molars. Int J Dentistry Oral Sci. 2020;S4:02:0012:63-68. doi: http://dx.doi.org/10.19070/2377-8075-SI02-040012

Copyright: Senthilnathan Periasamy 2020 . This is an open-access article distributed under the terms of the Creative Commons Attribution License, which permits unrestricted use, distribution and reproduction in any medium, provided the original author and source are credited. 
Their relationship with the second molar results in exposure of distal root surface of second molar to the oral environment, a second molar with distal cervical caries requires either restoration or extraction in addition to removal of the third molar. If the third molar is removed before cervical caries forms on the second molar then consequently dental treatment of this tooth is avoided [25] Mc Ardle and Renton reported a meaningful relationship between occurrence of distal caries on mandibular second molars and position of mandibular third molars, where $82 \%$ of the third molars had a mesial angulation between 40 degree to eighty degree.

Previously our team had conducted numerous studies which include in vitro studies [23], review [30], survey [21, 28, 32, 34] and clinical trials $[7,15,17,26,31,35,39]$. Now we are focussing on retrospective studies, and this study is aimed to evaluate the incidence of distal caries on mandibular second molars in patients referred for mesioangularly impacted mandibular third molar assessment.

\section{Materials and Methods}

This retrospective study was conducted among patients reporting to the outpatient dental department of oral surgery clinic at Saveetha Dental College, Chennai during the period between June 2019- March 2020.A total of 86000 patient records were reviewed and analysed. There were 167 patients with radiographically confirmed mesioangularly impacted mandibular third molars, out of which 98 were male and 69 were female.

\section{Inclusion Criteria}

- Patients above 18 years of age

- Patients with fully erupted mandibular second permanent molars adjacent to third molars

- Patients with radiographically confirmed mesioangularly impacted mandibular third molars

- Patients with signs and symptoms suggestive of mandibular third molar pathology

\section{Exclusion Criteria}

- Patients with missing mandibular second molars

- Patients with missing mandibular third molars- extracted or congenitally missing

- Patients below 18 years of age

- Patients with implants in second molars

- Patients with development disorders like microdontia, presence of 4th molars, impacted second molars, supernumerary teeth, odontomas.

\section{Diagnostic Criteria}

The orthopantomograms were taken as records for patients requiring assessment for mesioangularly impacted mandibular third molar. The angulation was evaluated based on Winters Classification (1926) which classifies third molars by their long axis and angulation with respect to long axis of the adjacent second molar as- Mesioangular, Distoangular, Horizontal and Vertical.
A record of the endodontic status of the adjacent second molar was also made, where the distal surfaces of the mandibular second molars were visually examined with the use of intraoral mirrors, and tactile examination with the use of dental explorers were also carried out.

The relationship between incidence of caries in mandibular second molars and eruption status of mandibular third molars were evaluated by reviewing dental records and panoramic radiographs.

\section{Study Parameters}

The data was recorded at an earlier date and the following data was extracted for the purpose of the study -:

- Age of the patient

- Gender of the patient

- Endodontic status of adjacent second molar

- Site of lower jaw affected

- Depth of mesioangular impacted mandibular based on Pell and Gregory Ramal Classification- Class 1, Class 2, Class 3.

- Level of mesioangularly impacted mandibular third molars based on Pell and Gregory Occlusal Classification- Position A, Position B, Position C.

The subjects were divided into five age groups- Group 1: 11-20 years, Group 2: 21-30 years, Group 3: 31-40 years, Group 4: 41-50 years, Group 5: 51-60 years.

\section{Data Collection}

The data related to the study parameters were obtained from among patients who reported to the Outpatient Department in Saveetha Dental College, Chennai from June 2019- March 2020. Approval for the study was obtained from the Institutional Ethical Committee of Saveetha University(SDC/SIHEC/2020/DIASDATA/0619-0320). All assessments were done by a single examiner and the findings were reviewed and recorded by two independent investigators. Written informed consent was obtained from the patients.

\section{Statistical Analysis}

The data was tabulated and analysed using IBM SPSS version 23.0 software. Non parametric data were analysed using descriptive statistics measuring frequency and percentage. Pearson's Chi Square Test was used to assess the association between side of the lower jaw frequently affected and incidence of distal caries adjacent to mandibular third molar.

\section{Results And Discussion}

A total of 167 cases of mesioangularly impacted mandibular third molars with complete clinical and radiographic records were included in this study.

\section{Age Distribution}

Among the 167 patients, 98 were male (58.7\%) and $69(41.3 \%)$ were female. The mean age of the patients was 27.8 years, with a range from 18-60 years. Among the 59 carious mandibular second 
molars, 33 patients $(55.9 \%)$ were found in patients between $21-30$ years, 14 patients $(23.7 \%)$ were found in patients between $31-40$ years, 11 patients (18.6\%) were found in patients between 11-20 years and 1 patient $(1.7 \%$ ) were found in patients between 41-50 years age group.

\section{Gender Distribution}

The distribution of study subjects based on gender showed that 30 patients $(50.8 \%)$ were female and 29 patients $(49.2 \%)$ were male among the 59 patients who showed an incidence of distal caries adjacent to mesioangular mandibular third molar.

\section{Presence of Distal Caries}

Out of the 167 cases with mesioangular impacted mandibular third molar, the incidence of distal caries on mandibular second molar was $35.33 \%$ (59 cases) with a predilection towards the left side of the lower jaw (50.84\%). However, the $\mathrm{p}$ value was $>0.05$, thus it was statistically insignificant.

\section{Depth of Impaction}

Out of the 59 patients, with clinical and radiographic evidence of distal caries on second molar, adjacent to mesioangularly impacted mandibular second molar, 50.8\% (30 patients) showed Position A, 21 patients $(35.6 \%)$ showed Position B, 8 patients $(13.6 \%)$ showed Position C.

\section{Ramus Relationship}

Out of 59 patients, with clinical and radiographic evidence of distal caries on second molar, adjacent to mesioangularly impacted mandibular third molar, there was higher incidence of caries with Class $2(52.24 \%)$, as compared to Class 1 ( 40.68\%) and Class 3 $(5.08 \%)$.

It is not surprising that distal caries in the second molar has become a significant concern among clinicians. The presentation of caries is highly variable; however, the risk factors and stages of development are similar. Its early detection is frequently challenging, thus the diagnosis is often made late in the disease process. Currently, the panoramic radiograph is the technique of choice to evaluate impacted mandibular third molars [12].

Allen et al [3] reported that mesioangular impacted third molars are 9.4 times more likely to have distal caries affecting the second molar when compared to any other angulations type [41]. Knuttson et al [19] reported that mesioangular and horizontal positioned third molars are more likely to be associated with caries development in adjacent second molars [41].

There are two schools of thought advocating prophylactic removal of third molars to preserve second molars. The preferential way being presence of a pathology and the second school of thought advocating prophylactic removal of third molar, as prevention is

Figure 1. The above pie chart represents the age as a baseline characteristics. From this pie chart we can infer that the age group frequently showing distal caries on 2nd molar adjacent to mesioangular impacted mandibular third molar was between $21-30$ years $(55.9 \%)$.

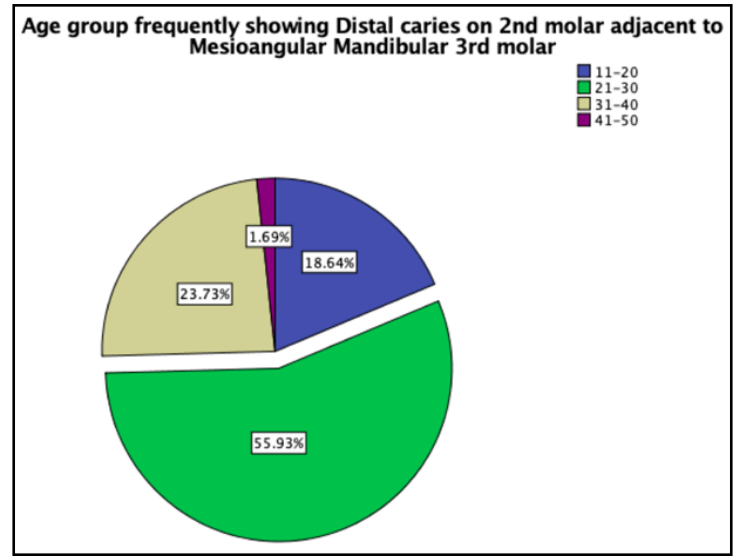

Figure 2. This bar graph represents the gender related baseline characteristics of patients. $X$ axis represents the gender and $\mathrm{Y}$ axis represents the frequency of patients. There was a higher incidence of females $(\mathbf{5 0 . 8 5} \%)$ presenting with distal caries on the mandibular 2nd molar adjacent to mesioangular impacted mandibular 3rd molar.

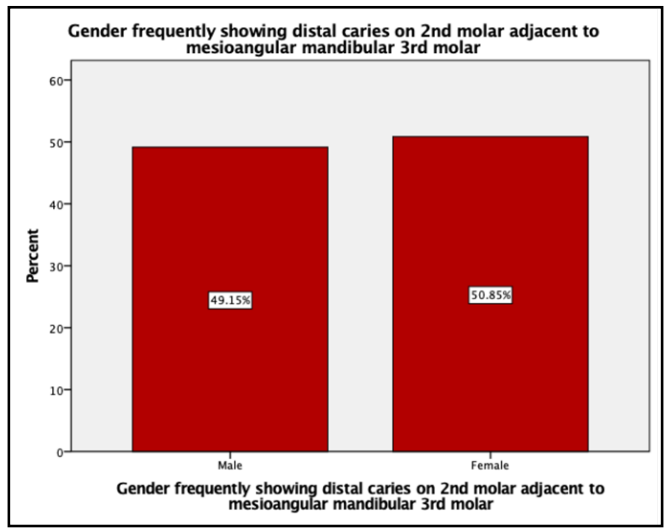


Figure 3. This pie chart depicts the presence of distal caries on 2 nd molar adjacent to mesioangularly impacted mandibular third molar. $35.33 \%$ patients showed presence of distal caries adjacent to mesioangular mandibular 3rd molar.

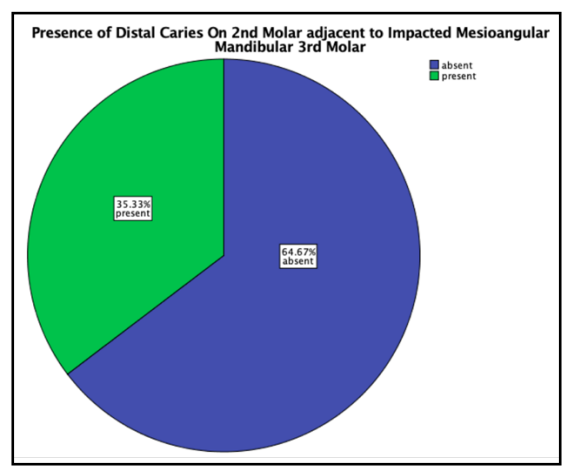

Figure 4. The above bar graph depicts the association between the side of lower jaw affected and the incidence of distal caries on the 2nd molar adjacent to mesioangularly impacted mandibular third molar . X-Axis represents the side of the lower jaw frequently affected and Y-Axis represents the incidence of distal caries on the 2nd molar. The Pearson's Chi Square Test was done to assess the association between side of the lower jaw frequently affected and incidence of distal caries adjacent to mandibular third molar. $\mathrm{p}>0.05$.

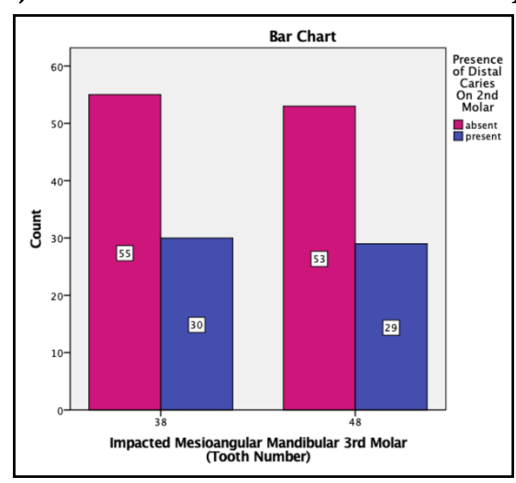

Figure 5. The above pie chart representsposition of mesioangularly impacted mandibular third molar with presence of distal caries on adjacent mandibular second molar. Majority of the patients, 30 Patients $(50.85 \%)$ out of 59 patients with distal caries on second molar presented with position A mesioangular 3rd molar.

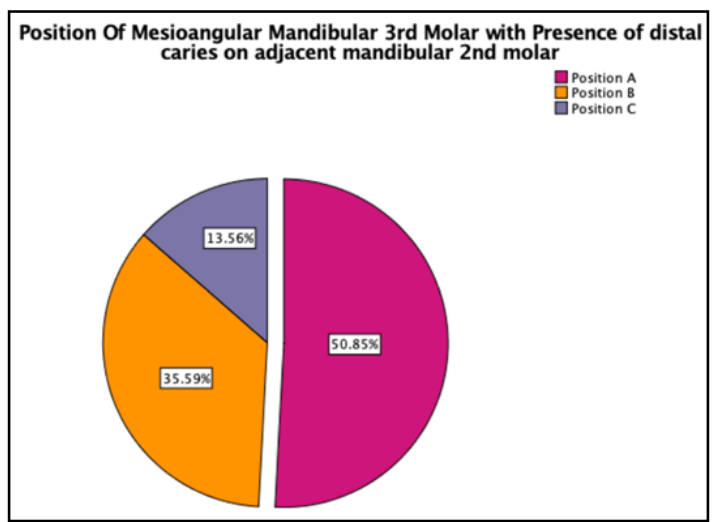

Figure 6. The above pie chart depicts the ramus relationship of mesioangular impacted mandibular 3rd Molar with presence of distal caries on adjacent mandibular second molar.Higher incidence of distal caries on mandibular 2 nd molar was seen in Class 2 Pell and Gregory Ramus Classification of mesioangular impacted mandibular 3rd molar (54.24\%).

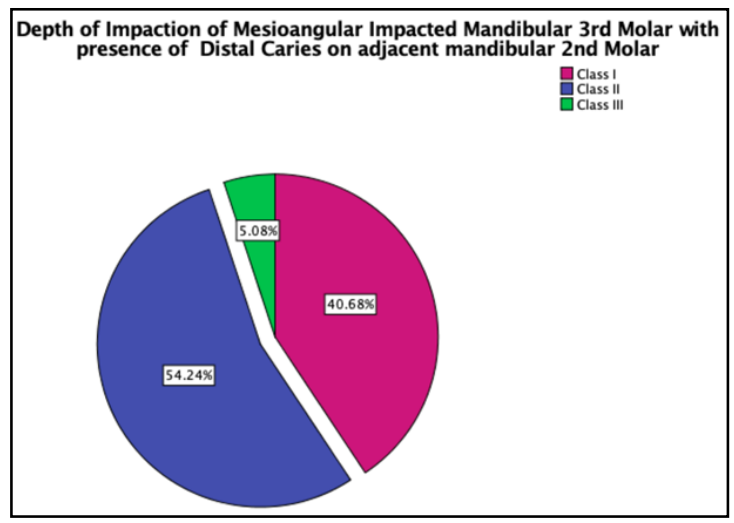


better than cure [33].

In our study, the mean age of patients presenting with mesioangular impacted third molar was 27.8 years with a range from 18-60 years, which was in accordance with the study by Mc Ardle et al [25]. According to Chang et al [6], a higher incidence of distal caries on mandibular second molars was found adjacent to mesioangular mandibular third molars between the age group of 21-30 years which was in accordance with our study. However, Ozec et al [29] showed that the incidence of distal caries on second molars increased with patients' age.

In our study, the incidence of distal caries on mandibular second molar adjacent to mesioangular impacted mandibular third molar was higher in females with a predilection towards left side of the lower jaw which is in accordance to the study by Falci et al (10). However, there was a higher incidence of males presenting with distal caries adjacent to mesioangular impacted third molar according to the study by Khanji et al [18] and Syed et al [40]. According to Toedtling [41], the incidence of distal caries in the second molar was significantly higher in subjects presenting with mesioangular impacted mandibular third molars $(p<0.001)$.

According to Allen et al [3], distal second molar caries were also significantly associated with mesioangular third molars. However, our study was statistically insignificant $(p$ value $=0.992)$ with the incidence of distal caries being 35.33\%(59 patients) out of 167 patients presenting with mesioangular impacted mandibular third molars. This could be due to use of panoramic radiographs, which have shown to be inferior to intraoral techniques in detecting interproximal caries. Therefore, early carious lesions may not have been detected, which might have led to an underestimation in the diagnosis of lower second molar distal caries [24].

In our study, out of 59 patients, presenting with clinical and radiographic evidence of distal caries in second molar, adjacent to mesioangular third molars, most patients presented with Position A (50.8\%) and Class $2(54.24 \%)$ mesioangular molars. This is in accordance with the study by $[10,38]$.

However, according to the study by Sheikh et al [37], majority of the mesioangular impacted third molars associated with carious mandibular second molars were in Position B and Class I Ramus Relationship.

\section{Limitations Of The Study}

The weak point of this study was use of extraoral panoramic radiographic studies to detect proximal caries. Early carious lesions with insufficient demineralization may not be detected. Since only advanced caries might have been detected,the false positive results may have been low.

\section{Future Scope}

Proper counselling at the primary visit would help in preventing further decay process of the second molars. Loss of tooth structure in relation to the second molar will lead to an advanced carious lesion, which harbours the need of early prophylactic removal of impacted third molar.

\section{Conclusion}

Prophylactic, early removal of mandibular mesioangular third molar can be considered in preventing distal caries affecting adjacent second molars. The presence and development of distal cervical caries in the second molar will require restorative and endodontic procedure along with removal of third molar. Within the limits of the study, there is presence of an association between the incidence of distal caries on mandibular second molar and adjacent mesioangular impacted mandibular third molar, with significant female predilection between the age group of 21-30 years. Therefore, such parameters should be considered by clinicians during assessment of mesioangular impacted mandibular third molars to prevent distal surface caries on adjacent second molars.

\section{References}

[1]. Abhinav RP, Selvarasu K, Maheswari GU, Taltia AA. The Patterns and Etiology of Maxillofacial Trauma in South India. Ann Maxillofac Surg. 2019 Jan-Jun;9(1):114-117. Pubmed PMID: 31293938.

[2]. Adeyemo WL. Do pathologies associated with impacted lower third molars justify prophylactic removal? A critical review of the literature. Oral Surg Oral Med Oral Pathol Oral Radiol Endod. 2006 Oct;102(4):448-52. Pubmed PMID: 16997110.

[3]. Allen RT, Witherow H, Collyer J, Roper-Hall R, Nazir MA, Mathew G. The mesioangular third molar--to extract or not to extract? Analysis of 776 consecutive third molars. Br Dent J. 2009 Jun 13;206(11):E23; discussion 586-7. Pubmed PMID: 19498427.

[4]. Almendros-Marqués N, Alaejos-Algarra E, Quinteros-Borgarello M, BeriniAytés L, Gay-Escoda C. Factors influencing the prophylactic removal of asymptomatic impacted lower third molars. Int J Oral Maxillofac Surg. 2008 Jan;37(1):29-35. Pubmed PMID: 17913461.

[5]. Aysha S. Angulations of impacted mandibular third molar: a radiographic study in Saveetha Dental College. Journal of Pharmaceutical Sciences and Research. 2015 Nov 1;7(11):981.

[6]. Chang SW, Shin SY, Kum KY, Hong J. Correlation study between distal caries in the mandibular second molar and the eruption status of the mandibular third molar in the Korean population. Oral Surg Oral Med Oral Pathol Oral Radiol Endod. 2009 Dec;108(6):838-43. Pubmed PMID: 19846329.

[7]. Christabel A, Anantanarayanan P, Subash P, Soh CL, Ramanathan M, Muthusekhar MR, et al. Comparison of pterygomaxillary dysjunction with tuberosity separation in isolated Le Fort I osteotomies: a prospective, multi-centre, triple-blind, randomized controlled trial. Int J Oral Maxillofac Surg. 2016 Feb;45(2):180-5. Pubmed PMID: 26338075.

[8]. Chu FC, Li TK, Lui VK, Newsome PR, Chow RL, Cheung LK. Prevalence of impacted teeth and associated pathologies--a radiographic study of the Hong Kong Chinese population. Hong Kong Med J. 2003 Jun;9(3):158-63. Pubmed PMID: 12777649.

[9]. Elter JR, Offenbacher S, White RP, Beck JD. Third molars associated with periodontal pathology in older Americans. J Oral Maxillofac Surg. 2005 Feb;63(2):179-84. Pubmed PMID: 15690285.

[10]. Falci SG, de Castro CR, Santos RC, de Souza Lima LD, Ramos-Jorge ML, Botelho AM, et al. Association between the presence of a partially erupted mandibular third molar and the existence of caries in the distal of the second molars. Int J Oral Maxillofac Surg. 2012 Oct;41(10):1270-4. Pubmed PMID: 22464852.

[11]. Flick WG. The third molar controversy: framing the controversy as a public health policy issue. J Oral Maxillofac Surg. 1999 Apr;57(4):438-44; discussion 445. Pubmed PMID: 10199496.

[12]. Gupta B. 'RADI OLOGICAL ASSESSMENT OF IMPACTED MANDIBULAR THIRD MOLAR TEETH'. 2017.

[13]. Halmos DR, Ellis E 3rd, Dodson TB. Mandibular third molars and angle fractures. J Oral Maxillofac Surg. 2004 Sep;62(9):1076-81. Pubmed PMID: 15346357.

[14]. Harsha S. Incidence of Mandibular Third Molar Impaction in Patients Visiting A Private Dental College. IOSR Journal of Dental and Medical Sciences. 2014;13(1):1-2.

[15]. Vijayakumar Jain S, Muthusekhar MR, Baig MF, Senthilnathan P, Loganathan S, Abdul Wahab PU, et al. Evaluation of Three-Dimensional Changes in Pharyngeal Airway Following Isolated Lefort One Osteotomy for the Correction of Vertical Maxillary Excess: A Prospective Study. J Maxillofac Oral Surg. 2019 Mar;18(1):139-146. Pubmed PMID: 30728705. 
[16]. Jajashree KA, Senthilnathan KP, Kumar MP. Association between impacted mandibular third molars and distal caries in second molars-A radiographic study. Research Journal of Pharmacy and Technology. 2018;11(6):2309-12.

[17]. Jesudasan JS, Wahab PU, Sekhar MR. Effectiveness of $0.2 \%$ chlorhexidine gel and a eugenol-based paste on postoperative alveolar osteitis in patients having third molars extracted: a randomised controlled clinical trial. $\mathrm{Br}$ Oral Maxillofac Surg. 2015 Nov;53(9):826-30. Pubmed PMID: 26188932.

[18]. Khanji A, Ali S, Duarte C. Prevalence of Distal Caries in Mandibular Second Molar Related to Impacted Third Molars in RAKCODS.

[19]. Knutsson K, Brehmer B, Lysell L, Rohlin M. Pathoses associated with mandibular third molars subjected to removal. Oral Surg Oral Med Oral Pathol Oral Radiol Endod. 1996 Jul;82(1):10-7. Pubmed PMID: 8843448.

[20]. Kruger E, Thomson WM, Konthasinghe P. Third molar outcomes from age 18 to 26: findings from a population-based New Zealand longitudinal study. Oral Surg Oral Med Oral Pathol Oral Radiol Endod. 2001 Aug;92(2):1505. pubmed PMID: 11505260.

[21]. Kumar S. and Sneha, S. Knowledge and awareness regarding antibiotic prophylaxis for infective endocarditis among undergraduate dental students', Asian Journal of Pharmaceutical and Clinical Research. 2016;154. doi: 10.22159/ajpcr.2016.v9s2.13405.

[22]. van der Linden W, Cleaton-Jones P, Lownie M. Diseases and lesions associated with third molars. Review of 1001 cases. Oral Surg Oral Med Oral Pathol Oral Radiol Endod. 1995 Feb;79(2):142-5. Pubmed PMID: 7614173.

[23]. Marimuthu M, Andiappan M, Wahab A, Muthusekhar MR, Balakrishnan A, Shanmugam S. Canonical Wnt pathway gene expression and their clinical correlation in oral squamous cell carcinoma. Indian J Dent Res. 2018 MayJun;29(3):291-297. Pubmed PMID: 29900911.

[24]. Marques J, Montserrat-Bosch M, Figueiredo R, Vilchez-Pérez MA, Valmaseda-Castellón E, Gay-Escoda C. Impacted lower third molars and distal caries in the mandibular second molar. Is prophylactic removal of lower third molars justified? J Clin Exp Dent. 2017 Jun 1;9(6):e794-e798. Pubmed PMID: 28638558.

[25]. McArdle LW, Renton TF. Distal cervical caries in the mandibular second molar: an indication for the prophylactic removal of the third molar? $\mathrm{Br}$ J Oral Maxillofac Surg. 2006 Feb;44(1):42-5. Pubmed PMID: 16213635.

[26]. Kumar S. Relationship between dental anxiety and pain experience during dental extractions. Asian Journal of Pharmaceutical and Clinical Research. 2017;10(3):458-

[27]. Kumar S. The emerging role of botulinum toxin in the treatment of orofacial disorders: Literature update. Asian Journal of Pharmaceutical and Clinical Research. 2017;10(9):21-9.

[28]. Kumar S, Rahman RE. Knowledge, awareness, and practices regarding biomedical waste management among undergraduate dental students. Asian Journal of Pharmaceutical and Clinical Research. 2017;10(8):341

[29]. Ozeç I, Hergüner Siso S, Taşdemir U, Ezirganli S, Göktolga G. Prevalence and factors affecting the formation of second molar distal caries in a Turkish population. Int J Oral Maxillofac Surg. 2009 Dec;38(12):1279-82. Pubmed PMID: 19665355

[30]. Packiri S, Gurunathan D, Selvarasu K. Management of Paediatric Oral Ran- ula: A Systematic Review. J Clin Diagn Res. 2017 Sep;11(9):ZE06-ZE09. Pubmed PMID: 29207849.

[31]. Patil SB, Durairaj D, Suresh Kumar G, Karthikeyan D, Pradeep D. Comparison of Extended Nasolabial Flap Versus Buccal Fat Pad Graft in the Surgical Management of Oral Submucous Fibrosis: A Prospective Pilot Study. J Maxillofac Oral Surg. 2017 Sep;16(3):312-321. Pubmed PMID: 28717289.

[32]. Patturaja K, Pradeep D. Awareness of Basic Dental Procedure among General Population. Research Journal of Pharmacy and Technology. 2016 Sep $1 ; 9(9): 1349$

[33]. Pentapati KC, Gadicherla S, Smriti K, Vineetha R. Association of impacted mandibular third molar with caries on distal surface of second molar. Pesquisa Brasileira em Odontopediatria e Clínica Integrada. 2019;19.

[34]. Rahman RE, Mp SK. Knowledge, attitude, and awareness of dental undergraduate students regarding human immunodeficiency virus/acquired immunodeficiency syndrome patients. Asian J Pharm Clin Res [Internet]. 2017; 10(5):175-80.

[35]. Rao TD, Kumar MS. Analgesic efficacy of paracetamol vs ketorolac after dental extractions. Research Journal of Pharmacy and Technology. 2018 Aug $1 ; 11(8): 3375-9$

[36]. Saysel MY, Meral GD, Kocadereli I, Taşar F. The effects of first premolar extractions on third molar angulations. Angle Orthod. 2005 Sep;75(5):71922. Pubmed PMID: 16287223.

[37]. Sheikh MA, Riaz M, Shafiq S. INCIDENCE OF DISTAL CARIES IN MANDIBULAR SECOND MOLARS DUE TO IMPACTED THIRD MOLARS--A CLINICAL \& RADIOGRAPHIC STUDY. Pakistan Oral \& Dental Journal. 2012 Dec 1;32(3).

[38]. Srivastava N, Shetty A, Goswami RD, Apparaju V, Bagga V, Kale S. Incidence of distal caries in mandibular second molars due to impacted third molars: Nonintervention strategy of asymptomatic third molars causes harm? A retrospective study. Int J Appl Basic Med Res. 2017 Jan-Mar;7(1):15-19. Pubmed PMID: 28251102.

[39]. Sweta VR, Abhinav RP, Ramesh A. Role of Virtual Reality in Pain Perception of Patients Following the Administration of Local Anesthesia. Ann Maxillofac Surg. 2019 Jan-Jun;9(1):110-113. Pubmed PMID: 31293937.

[40]. Syed KB, Alshahrani FS, Alabsi WS, Alqahtani ZA, Hameed MS, Mustafa AB, Alam T. Prevalence of Distal Caries in Mandibular Second Molar Due to Impacted Third Molar. J Clin Diagn Res. 2017 Mar;11(3):ZC28-ZC30. Pubmed PMID: 28511504.

[41]. Toedtling V, Coulthard P, Thackray G. Distal caries of the second molar in the presence of a mandibular third molar - a prevention protocol. Br Dent J. 2016 Sep 23;221(6):297-302. Pubmed PMID: 27659630.

[42]. Ventä I, Schou S. Accuracy of the Third Molar Eruption Predictor in predicting eruption. Oral Surg Oral Med Oral Pathol Oral Radiol Endod. 2001 Jun;91(6):638-42. Pubmed PMID: 11402274.

[43]. Yee WS, Rahman RA, Taib H. Effects of lower third molar removal on attachment level and alveolar bone height of the adjacent second molar. Arch of Orofacial Sci. 2009 Jan 1;4(2):36-40. 